\title{
Optimization of ex vivo hematopoietic stem cell expansion in intermittent dynamic cultures
}

\author{
Yong-Soo Choi $\cdot$ Sang-Eun Noh $\cdot$ Sang-Min Lim • \\ Dong-il Kim
}

Received: 16 May 2010/Accepted: 9 July 2010/Published online: 22 July 2010

(C) The Author(s) 2010. This article is published with open access at Springerlink.com

\begin{abstract}
For the ex vivo expansion of $\mathrm{CD} 34^{+}$ cells, culture conditions were optimized using cytokine cocktails and media change methods. In addition, static, orbital-shake, and stirred cultures were compared. After cultivation, total cell expansion, immunophenotypes, clonogenic ability, and metabolite concentration in media were analyzed. Optimized media change methods enhanced the number of total nucleated cells (TNCs) by 600 -fold (from $10^{4}$ to $6 \times 10^{6}$ cells) in static cultures. Furthermore, intermittent orbital-shake cultures gave the highest fold increase of $\mathrm{TNCs}$ and $\mathrm{CD} 34^{+} / \mathrm{CD} 38^{-}$cells. These results imply that proliferation of $\mathrm{CD} 34^{+}$cells in intermittent shake cultures was more efficient than that in static cultures under optimized culture conditions.
\end{abstract}

Purpose of work We have investigated the optimal conditions for ex vivo expansion of $\mathrm{CD} 34^{+}$cells with various cytokine combinations and media change methods as a preliminary, but necessary, step for their subsequent use for engraftment into adult patients.

\section{Y.-S. Choi}

Department of Applied Bioscience, CHA University, Seoul 135-081, Korea

\section{S.-E. Noh}

CHA Bio \& Diostech, Seoul 135-833, Korea

\section{S.-M. Lim · D. Kim ( ()}

Department of Biological Engineering, Inha University, Incheon 402-751, Korea

e-mail: kimdi@inha.ac.kr
Keywords Dynamic culture $\cdot$ Hematopoietic stem cells $\cdot$ Self-renewal expansion $\cdot$ Umbilical cord blood

\section{Introduction}

Hematopoietic stem cells (HSCs) can be obtained from bone marrow (BM), umbilical cord blood (UCB), and mobilized peripheral blood (PB). Among these sources, UCB has recently been the focus of clinical applications due to its relative accessibility, its high number of primitive progenitor cells (Mayani and Lansdorp 1998), and its relatively low frequency of graft-versus-host disease (Wagner et al. 2002). However, due to the low number of $\mathrm{CD} 34^{+}$cells in UCB, ex vivo expansion is required for engraftment into adult patients (Gluckman et al. 1989). For optimum engraftment, current transplantation requires at least $2.5 \times 10^{6} \mathrm{CD}^{+} 4^{+}$cells per $\mathrm{kg}$ patient body weight (Rocha et al. 2000).

To date, various strategies have been employed for the improvement of HSC expansion in vitro. One such method is the ex vivo cultivation of $\mathrm{CD} 34^{+}$cells with recombinant cytokines such as SCF, IL-3, IL-6, FL, TPO, etc. (McNiece and Briddell 2001). However, the optimal combination and concentration of cytokines have not been determined (Heike and Nakahata 2002). In addition to cytokines, different types of bioreactors were developed and investigated. Koller et al. (1993) reported that continuous perfusion cultivation of HSCs from BM cells for large-scale expansion 
resulted in the tenfold expansion of total nucleated cells (TNCs) for 14 days. Collins et al. (1998) described the successful application of spinner flask culture to hematopoietic cells. In addition, Liu et al. (2006) reported that a rotating wall vessel could provide a better environment for the expansion of UCB MNCs. However, no one has tried to culture HSCs in orbital-shake flasks, which can provide a lower physical force environment than spinner flasks.

In this study, the optimal conditions for ex vivo expansion of $\mathrm{CD}^{+} 4^{+}$cells were investigated using various cytokine combinations and media change methods. In addition, comparison of the proliferation and selfrenewal capacity of $\mathrm{CD} 34^{+}$cells under static, orbitalshake, and stirred culture conditions were performed.

\section{Materials and methods}

Cultivation of $\mathrm{CD} 34^{+}$cells

After separation of mononuclear cells (MNCs) from $\mathrm{UCB}$ as described in our previous reports (Choi et al. 2008), CD34 ${ }^{+}$cells were enriched using EasySep (StemCell Technologies, BC, Canada) according to the manufacturer's instructions. Enriched $\mathrm{CD} 34^{+}$cells were cultured under static and dynamic conditions in serum-free medium, StemSpan (StemCell Technologies, BC, Canada). Recombinant human stem cell factor (SCF), flt $3 / f l t 2$ ligand (FL), thrombopoietin (TPO), interleukin-3 (IL-3), IL-6, granulocyte colony-stimulating factor (G-CSF), and granulocyte-macrophage colony-stimulating factor (GM-CSF) (Sigma-Aldrich, Inc., MO, USA) were used. Culture media were changed every 3 days, and the cultures were maintained at $37^{\circ} \mathrm{C}$ in a humidified atmosphere containing $5 \% \mathrm{CO}_{2}$.

Static and intermittent dynamic cultures

Static cultures were performed by different methods and are summarized as brief diagrams (Fig. 1). In method A, conditioned medium was exchanged with fresh medium at a half volume of initial medium. In method B, fresh medium was continuously added to culture dishes at the same volume of initial medium. In method $\mathrm{C}$, half of the conditioned medium was removed after which fresh medium was added at a threefold volume of conditioned medium. These cells were then concurrently transferred to a culture dish that was bigger than the previous one. In method D,
Fig. 1 Diagram of different media exchange methods in static cultures. Conditioned medium were exchanged with fresh medium at half volume (a); fresh media were continuously added at the same volume into conditioned medium (b); a half volume of conditioned medium was removed after which fresh medium were added at a threefold volume of the conditioned medium. These cells were then concurrently transferred to a culture dish that was bigger than the previous one (c); total conditioned medium were exchanged with fresh medium at a twofold volume of conditioned medium (d). The medium was changed every 3 days
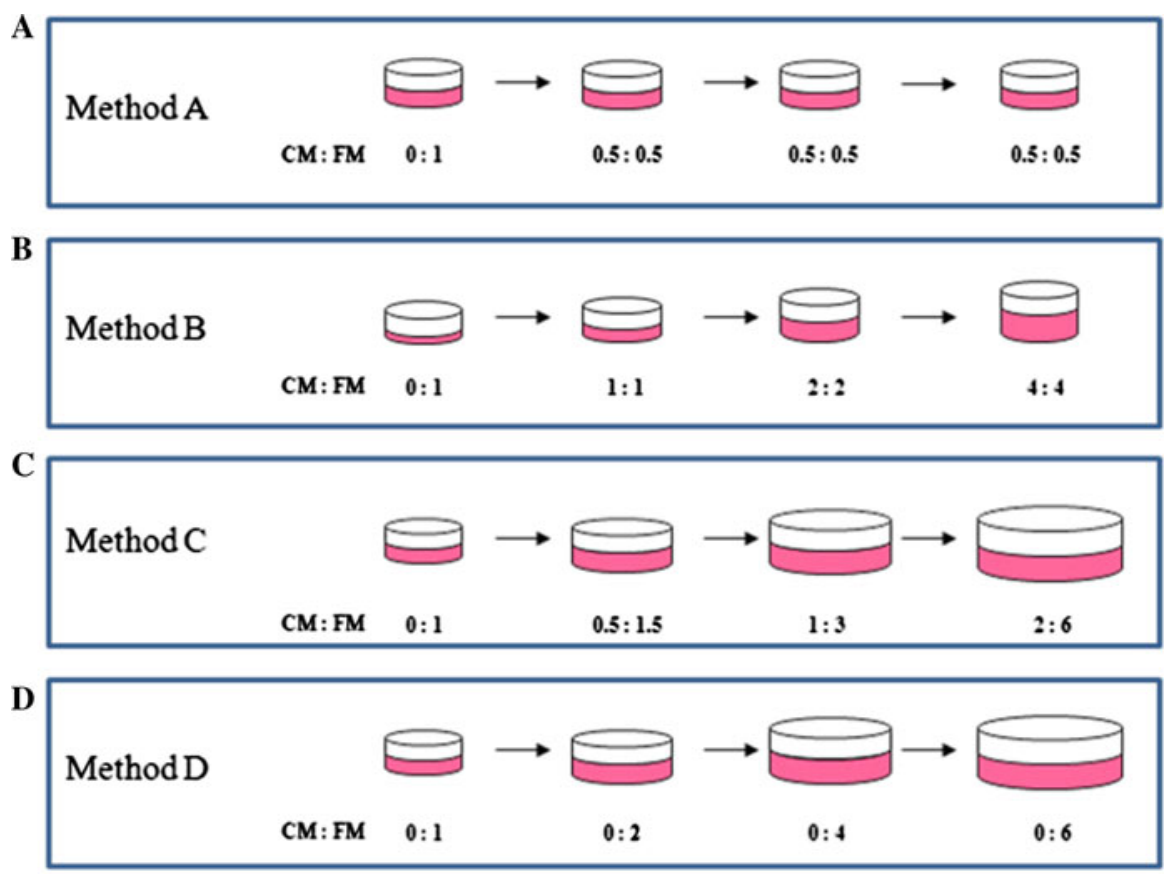

CM: conditioned media FM: fresh media 
total conditioned medium was exchanged with a twofold volume of fresh medium.

Shake cultures were performed using $10 \mathrm{ml}$ culture medium in $125 \mathrm{ml}$ Erlenmeyer flasks with intermittent shaking at $30 \mathrm{rpm}$ for $15 \mathrm{~min}$ on and off intervals.

Stirred cultures were performed using $10 \mathrm{ml}$ culture medium in $50 \mathrm{ml}$ spinner flasks (StemCell Technologies, BC, Canada) with agitation at $30 \mathrm{rpm}$ using a low-speed stirrer.

The ratio of the number of TNCs to the number of inoculated $\mathrm{CD} 34^{+}$cells was represented by the fold increase. Based on previous reports (Collins et al. 1998), the inoculum and maintenance density were at $5 \times 10^{4}$ and $10^{6}$ cells $/ \mathrm{ml}$, respectively.

Colony forming cell assay

Assays for clonogenic progenitors from expanded HSCs were performed in MethoCult GF H4434 (StemCell Technologies, BC, Canada) using freshly isolated and expanded 500 cells. At the end of the incubation period, colonies of 50 or more cells were enumerated as CFU-GM (including CFU-G and CFU-M), BFU-E, or CFU-Mix by bright-field inverted microscopy (Olympus, PA, USA).

Immunophenotypic analysis

The isolated and expanded cells were characterized by flow cytometry using the following FITC- or PEcoupled anti-human antibodies: CD34, CD38, CD45 (Becton-Dickinson, NJ, USA), and mouse $\mathrm{IgG}_{1}$ as an isotypic control. 7-Amino-actinomycin $\mathrm{D}$ (7AAD; Becton-Dickinson, NJ, USA) was used for the exclusion of nonviable cells. All reaction mixtures were then analyzed via FACSCalibur (Becton-Dickinson, CA, USA) using CellQuest Pro and WinMDI 2.9 software.

\section{Results}

Optimal combination of cytokines

To determine the optimal combination and concentration of cytokines, five different conditions were tested using seven cytokines that are known to be effective in HSC expansion. Table 1 shows the various combinations and concentrations of
Table 1 Different combinations and concentrations of hematopoietic cytokines $(\mathrm{ng} / \mathrm{ml})$

\begin{tabular}{rrrrrrcc}
\hline & SCF & Flt-3 & IL-3 & IL-6 & TPO & G-CSF & GM-CSF \\
\hline A & 0 & 0 & 0 & 0 & 0 & 0 & 0 \\
B & 100 & 100 & 100 & 100 & 100 & 100 & 100 \\
C & 100 & 100 & 20 & 20 & 0 & 0 & 0 \\
D & 100 & 100 & 0 & 0 & 100 & 0 & 0 \\
$\mathrm{E}$ & 50 & 0 & 10 & 0 & 50 & 0 & 0 \\
\hline
\end{tabular}

cytokines. Cytokine cocktails C, D, and E were referred by the concentration of commercial products. After inoculation of $\mathrm{CD}_{3} 4^{+}$cells in serum-free media, short-term cultivation of each cocktail showed that cytokine cocktails $\mathrm{C}$ and $\mathrm{D}$ had positive effects on cell proliferation (data not shown). Therefore, a new cytokine cocktail, a combination of cytokine cocktails C and D composed of $100 \mathrm{ng} \mathrm{SCF} / \mathrm{ml}$, Flt-3, and TPO along with $20 \mathrm{ng}$ IL-3 and IL-6/ml, was investigated. TNCs with cocktail D experienced 25-fold expansion at day 6, whereas the fold expansion was 46-fold at day 5 with the new cocktail. Therefore, this new cytokine cocktail was used in the following experiments as the optimal combination.

Optimization of media change in static cultures

Different media change methods were investigated for their ability to maintain cell density and conditioning factors. In the first experiments, a conventional method (half media change, method A) was compared with method B (adding the same volume of media). Due to increased cell density during culturing, method B showed higher proliferation than method A (Fig. 2a). In addition, an increase in CFCs cultured by method B resulted in 116-fold expansion (Fig. 2b). These results imply that maintenance of optimal cell density during culturing affected $\mathrm{CD} 34^{+}$cell proliferation. To maintain cell density, the total volume of medium was increased (methods $\mathrm{C}, \mathrm{D}$ ). The maximum expansion of $\mathrm{CD} 34^{+}$cells was over 600 -fold (from $10^{4}$ cells to $6.1 \times 10^{6}$ cells) by method $\mathrm{C}$ at day 15 (Fig. 3). Moreover, another experiment showed that the total fold increase of CD34 ${ }^{+}$cells by method $\mathrm{C}$ at day 17 was 1,230 -fold (data not shown). These results imply that method $\mathrm{C}$ was reproducible. 

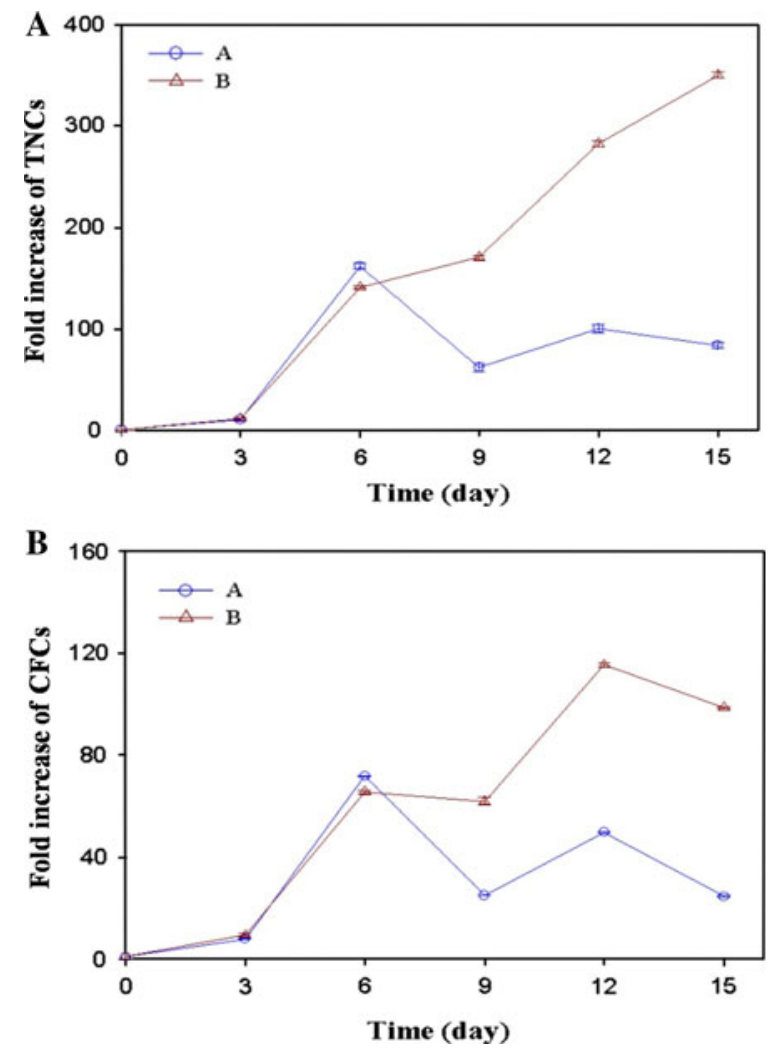

Fig. 2 Fold increase of TNCs (a) and colony-forming cells (b) cultured by half-media change $(\operatorname{method} A)$ and same volume addition (method $B$ ) methods in static cultures. The cells were cultured in serum-free medium containing an optimized combination of cytokines $(100 \mathrm{ng} / \mathrm{ml} \mathrm{SCF}$, TPO and Flt-3; $20 \mathrm{ng} / \mathrm{ml} \mathrm{IL-3} \mathrm{and} \mathrm{IL-6)} \mathrm{for} 2$ weeks. The initial concentration of HSCs was $10^{4}$ cells $/ 0.4 \mathrm{ml}$ medium. Every 3 days, expanded 500 cells were seeded in colony assay medium. After 2 week's incubation, colonies were enumerated

Comparison of static and dynamic cultures

After thawing of $\mathrm{CD} 34^{+}$cells frozen in liquid $\mathrm{N}_{2}$, direct cultivation in shake or stirred flasks causes cell death. To overcome this problem, static pre-cultures were performed for 3 days before inoculation of the cells into shaken and stirred flasks. This pre-incubation period avoided a lag phase in the dynamic cultures and had the effect of enhancing cell viability. After cultivation in static and dynamic cultures for 9 days, the immunophenotypes of the expanded cells were analyzed. In the case of stirred cultures, expanded cells experienced a lost in the CD34 ${ }^{+}$ marker phenotype by $0.14 \%$ (Fig. 4 ). Therefore, we

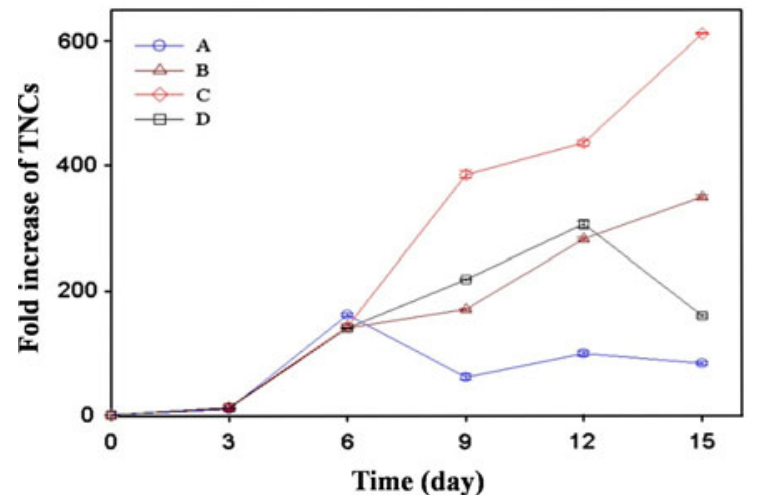

Fig. 3 Fold increase of TNCs cultured by different media change methods which were showed in Fig. 1. The initial concentration of HSCs was at $10^{4}$ cells $/ 0.4 \mathrm{ml}$ medium

did not perform stirred cultures with freshly isolated $\mathrm{CD}^{+} 4^{+}$cells. However, when cultured under static and intermittent shake conditions, freshly isolated $\mathrm{CD} 4^{+}$cells were similarly maintained (Fig. 5). The expansion of TNCs in shake cultures was higher than that in static cultures. Consequently, TNCs and $\mathrm{CD} 34^{+} / \mathrm{CD} 38^{-}$cells in shake cultures experienced 1.2- and 1.25-fold higher expansion, respectively, compared to those in static cultures at day 9 (Fig. 6). In addition, the concentrations of metabolites such as lactic acid, glucose, ammonia, and glutamine in intermittent shake cultures were similar with those in static cultures (data not shown). However, intermittent shake cultures were more efficient in maintaining CD $34^{+} / \mathrm{CD} 38^{-}$cells.

\section{Discussion}

Over the past decade, various different types of bioreactors, such as the stirred bioreactor, fixed-bed bioreactor, perfusion chamber, hollow fiber, airlift packed bed, and rotating wall vessel, have been tested for the expansion of HSCs (Koller et al. 1993, 1998; Cabral 2001; Liu et al. 2001; Collins et al. 1998). In this study, the use of intermittent shake and stirred cultures was investigated for the expansion of UCBderived $\mathrm{CD} 34^{+}$cells in serum-free media containing cytokine cocktails. In addition, cytokine combination and media change methods were optimized for the promotion of cell growth. 
Fig. 4 Immunophenotypes of expanded cells in static and dynamic cultures with thawed $\mathrm{CD} 34^{+}$cells at day 9 . These cells were precultured for 3 days in static condition before inoculation of the cells into shake-flasks
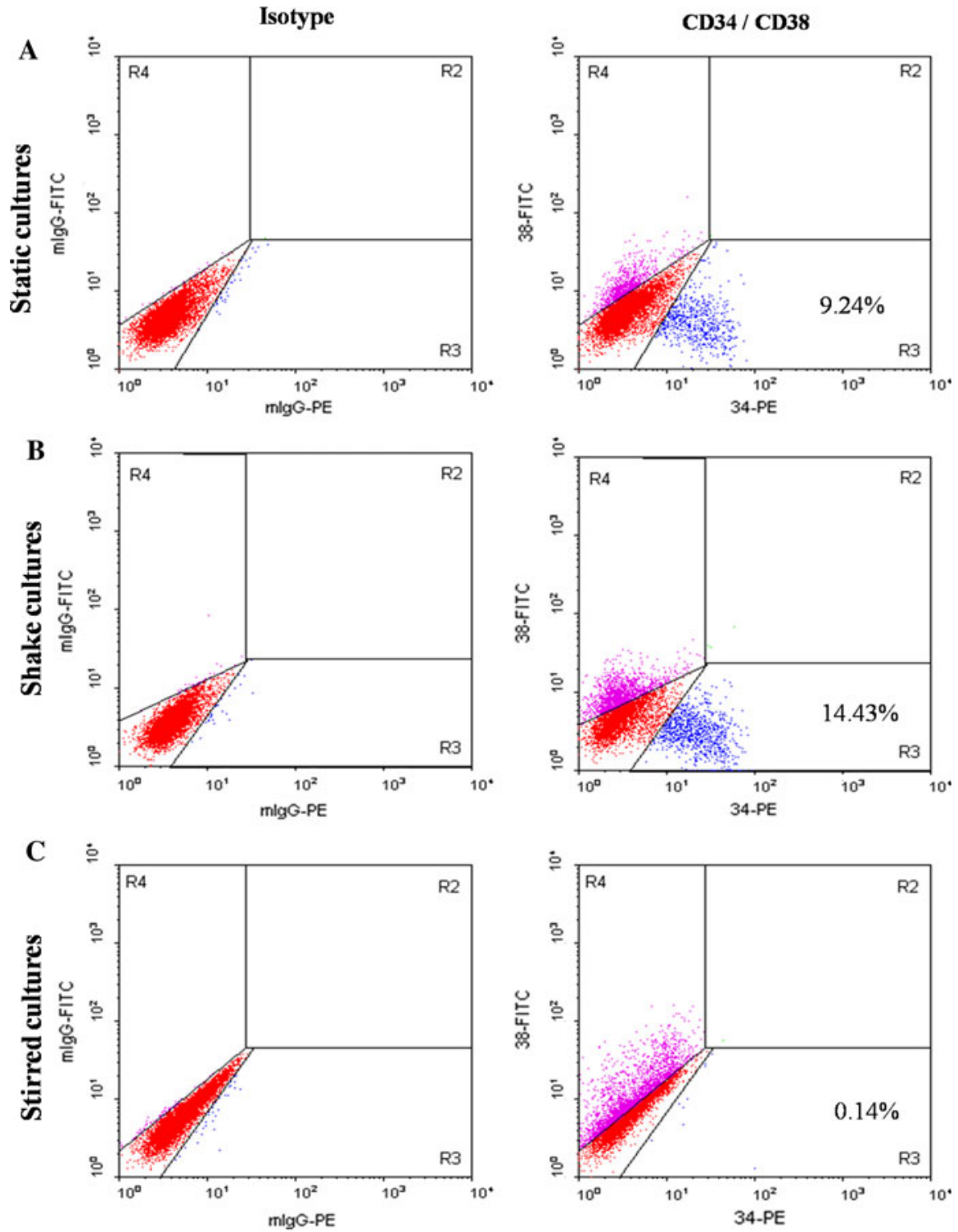

In general, half of the conditioned medium under static conditions is exchanged with fresh medium. However, since cell density increases gradually during the culture period, a half-media change is not sufficient for the optimization of culture conditions. To maintain the volumetric cell density of cultures, the cells were transferred or divided into other plates. In this situation, the shake-culture system has some advantages over traditional T-flasks. First, since the shake-culture system easily increases the volume of culture media for maintaining cell density, the cells need not be transferred into other flasks. In contrast, T-flask cultures are limited in productivity by the number of HSCs supported by a given surface area. Second, although T-flask cultures make high concentration gradients (e.g., cells, nutrients, metabolites and cytokines) (Collins et al. 1998), the shake culture system can provide a suspension environment in the medium in which all cells can be suspended and this overcomes the concentration gradients. Third, there are less physical shear forces in the shake-cultures compared to stirred conditions. 
Fig. 5 Immunophenotypes of expanded cells in static and dynamic cultures with freshly isolated CD34 ${ }^{+}$ cells at day 9
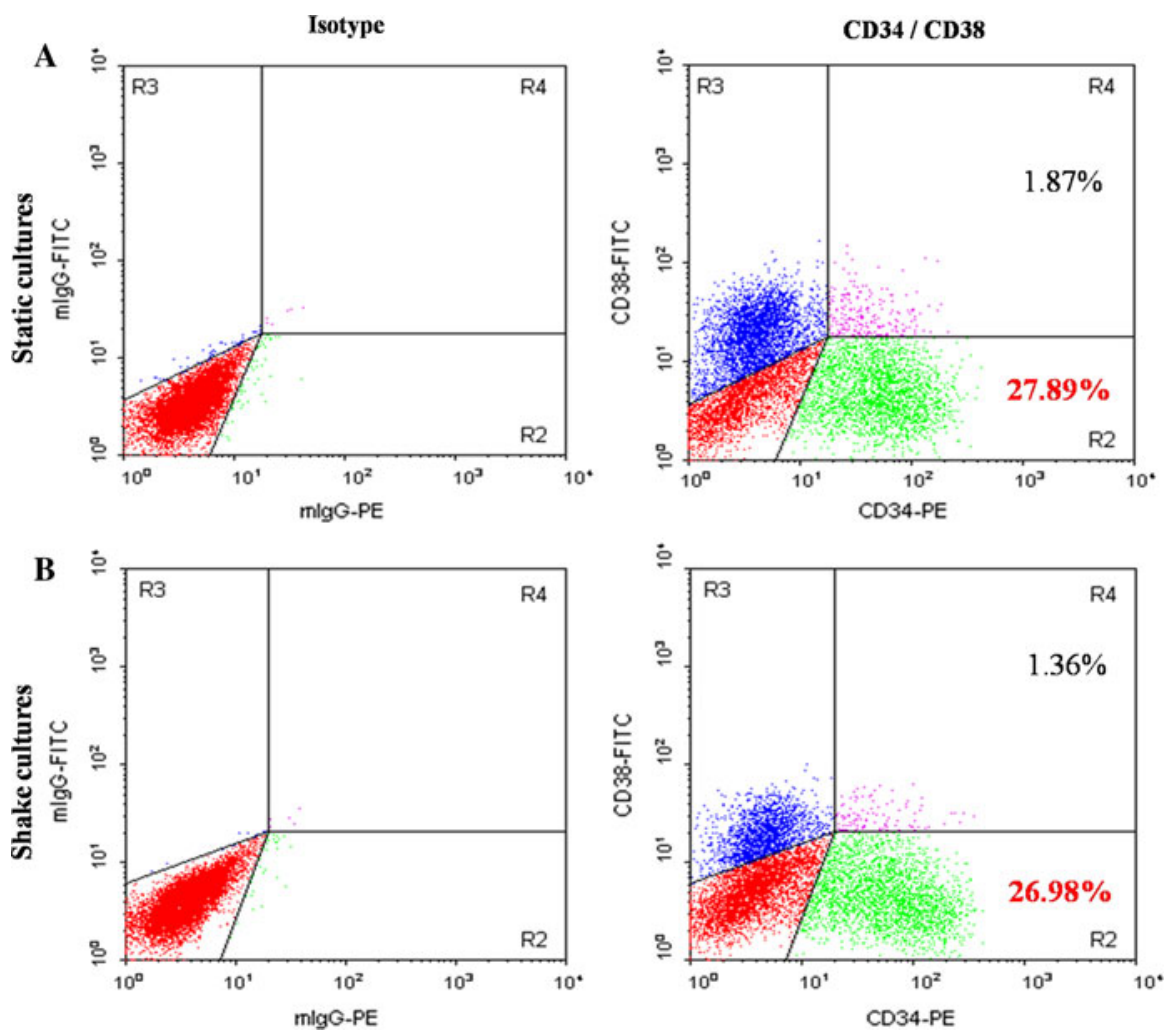

Finally, cell damage caused by air bubble-rupture did not occur in the shake system at low-speed. As discussed by Michaels et al. (1996), the majority of shear-related cell damage that occurs in stirred systems is the result of air bubble-rupture by headspace gas. Although the effects of shear force on cellular mechanisms have not been determined, it is true that shear force damages HSCs in stirred cultures.

Inoculum cell density and the maintenance of optimal cell density are important factors during culture. Therefore, dilution-type feeding protocols were used for maintaining cell density by removing the cells from bioreactor cultures (Liu et al. 2006; Collins et al. 1998). Similarly, McNiece et al. (2000) reported that a two-step expansion culture of TNCs resulted in an expansion of 438 -fold. HSCs were inoculated in $100 \mathrm{ml}$ medium and cultured for 7 days, after which the cells were transferred into $1000 \mathrm{ml}$ medium. In contrast, the original one-step culture resulted in a 98 -fold expansion. These results imply that the maintenance of cell density is an essential factor for enhancing the proliferation of HSCs.

In conclusion, an optimized cytokine combination and media change methods improved the culture conditions of ex vivo $\mathrm{CD} 34^{+}$cell expansion. Furthermore, it was demonstrated that intermittent shake cultures provided a better environment for the expansion of $\mathrm{CD} 34^{+}$cells than static cultures. For practical clinical trials relating to HSC growth, the total volume of the culture media should be gradually increased in order to maintain optimal cell density. However, as the volume of culture media is increased, the use of high-priced cytokines should be increased. Therefore, we tried to develop novel culture systems for the expansion of $\mathrm{CD} 34^{+}$cells under serum-and cytokine-free conditions.

Acknowledgments This work was supported by the Korea Research Foundation through the BrainKorea (BK) 21 Industrial Biotechnology \& Marine Resources Center in Inha University. 

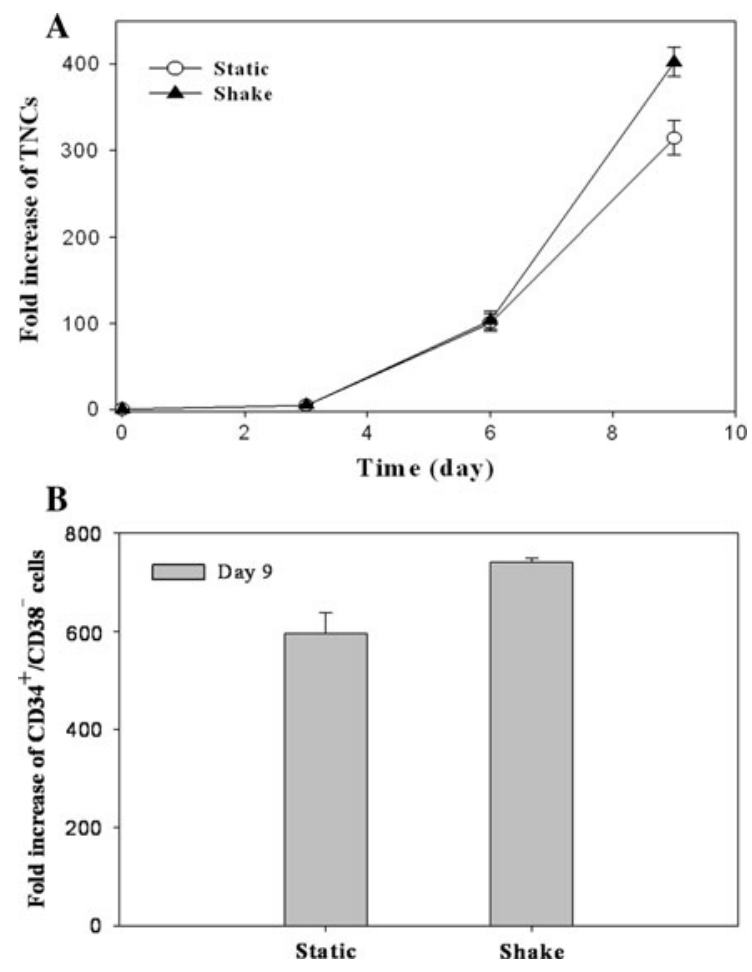

Fig. 6 Fold increase of TNCs (a) and CD $34^{+} / \mathrm{CD} 38^{-}$(b) cells in static and dynamic cultures with fresh isolated cells for 9 days. The concentrations of the inoculum and maintenance density were at $5 \times 10^{4}$ and $10^{6}$ cells $/ \mathrm{ml}$, respectively

Open Access This article is distributed under the terms of the Creative Commons Attribution Noncommercial License which permits any noncommercial use, distribution, and reproduction in any medium, provided the original author(s) and source are credited.

\section{References}

Cabral JMS (2001) Ex vivo expansion of hematopoietic stem cells in bioreactors. Biotechnol Lett 23:741-751

Choi YS, Lim SM, Lee CW, Kim CS, Im MW, Lee MH, Kim DI (2008) Cytokine-free expansion of hematopoietic stem cells with mixed mesenchymal stem cells isolated from bone marrow and periosteum. J Tissue Eng Regen Med $5: 683-689$
Collins PC, Miller WM, Papoutsakis ET (1998) Stirred culture of peripheral and cord blood hematopoietic cells offers advantages over traditional static systems for clinically relevant applications. Biotechnol Bioeng 59:534-543

Gluckman E, Broxmeyer HA, Auerbach AD, Friedman HS, Douglas GW, Devergie A, Esperou H, Thierry D, Socie G, Lehn P (1989) Hematopoietic reconstitution in a patient with Fanconi's anemia by means of umbilical cord blood from an HLA-identical sibling. N Engl J Med 321: $1174-1178$

Heike T, Nakahata T (2002) Ex vivo expansion of hematopoietic stem cells by cytokines. Biochim Biophys Acta 1592:313-321

Koller MR, Emerson SG, Palsson Bǿ (1993) Large-scale expansion of human stem and progenitor cells from bone marrow mononuclear cells in continuous perfusion cultures. Blood 82:378-384

Koller MR, Manchel I, Maher RJ, Goltry KL, Armstrong RD, Smith AK (1998) Clinical-scale human umbilical cord blood cell expansion in a novel automated perfusion culture system. Bone Marrow Transplant 21:653-663

Liu Y, Liu T, Fan X, Ma X, Cui Z (2006) Ex vivo expansion of hematopoietic stem cells derived from umbilical cord blood in rotating wall vessel. J Biotechnol 124:592-601

Mayani H, Lansdorp PM (1998) Biology of human umbilical cord blood-derived hematopoietic stem/progenitor cells. Stem Cells 16:153-165

McNiece I, Briddell R (2001) Ex vivo expansion of hematopoietic progenitor cells and mature cells. Exp Hematol 29:3-11

McNiece I, Kubegov D, Kerzic P, Shpall EJ, Gross S (2000) Increased expansion and differentiation of cord blood products using a two-step expansion culture. Exp Hematol 28:1181-1186

Michaels JD, Mallik AK, Papoutsakis ET (1996) Sparging and agitation-induced injury of cultured animals cells: do cellto-bubble interactions in the bulk liquid injure cells? Biotechnol Bioeng 51:399-409

Rocha V, Wagner JE, Sobocinski KA, Klein JP, Whang MJ, Horowitz MM, Cluckman E (2000) Graft-versus-host disease in children who have received a cord-blood or bone marrow transplant from an HLA-indential sibling. Eurocord and international bone marrow transplant registry working committee on alternative donor and stem cell sources. N Engl J Med 342:1846-1854

Wagner JE, Barker JN, DeFor TE, Baker KS, Blazar BR, Eide C, Goldman A, Kersey J, Krivit W, MacMillan ML, Orchard PJ, Peters C, Weisdorf DJ, Ramsay NK, Davies SM (2002) Transplantation of unrelated donor umbilical cord blood in 102 patients with malignant and nonmalignant diseases: influence of CD34 cell dose and HLA disparity on treatment-related mortality and survival. Blood 100:1611-1618 